which is rarely the case in the male, and the green markings. which disappear towards the costa in the male, are there in the female replaced by long bifid grey streaks between the nervures. An interesting account of the habits of this species, as noticed by various observers, is given by Mr. Rippon in his "Icones Orthopterorum."

One other species of this genus is known: T. Trojana, Staudinger, from Palawan, an island about a hundred miles from the north coast of Borneo. Hiere the brassy-green spots of the fore wings of the male are shorter and more subconical, instead of forming long isosceles triangles, and there is only a row of connecied green spots across the hind wings, bordered within with blue; the base of the wings is also marked with rich blue across the nervures, and along the edge of the fold of the hind wings.

Some idea of the market value of conspicuous insects, before they are sent over in numbers, may be gathered from the circumstance that a specimen of this butterfly recently sold for $£$ I 5 at Stevens's auction rooms.

This is the last genus included in Ornithoptera which is met with in the East, but the two largest West African butterflies are likewise considered to belong to this group, and may receive a passing notice here. One of these is the famous Drurya Antimachus, which was brought by Smeathman from Sierra Leone, and figured by Drury in 1782 , and, afterwards, by Donovan in his " Naturalists' Repository," but of which no second specimen was seen in Europe till 1864 . It is an insect with very long and narrow wings, from seven to nearly nine inches in expanse, and much resembles some gigantic species of the very characteristic African genus $A c r a a$. It is black, with large tawny spots and markings toward; the base of the fore wings, the greater part of the hind wings is tawny, with a row of black submarginal spots. It has been suggested that this insect possibly mimics an extinct $A c r a a$, for the largest known species of that genus are not much more than half the size of D. Antimachus. The female is considerably smaller than the male (a raiher unusual character in butterflies), and has much shorter wings. There are two specimens in the Hewitson Col lection in the British Museum, and it was one of these that $\mathrm{Mr}$. Hewitson used to say cost him $£ 500$. The real explanation is probably that he spent that amount in sending out agents to collect butterflies in Africa, with special instructions to look for $D$. Antimachus. Of late years, many specimens have been brought to Europe, and the butterfly can now be bought at a comparatively reasonable price.

The other West African butterfly now recognised as belonging to the Ornithoptera group, but for which a new genus will probably be created before long, was described by Hewitson under the name of Papilio Zalmoxis. It measures about seven inches across the wings, which are broader and more rounded than in the typical Eastern butterfies of this group. The male is of a rather pale blue, with black borders, slightly spotted with blue on the hind wings, and with black marginal lines between the nervures, and a black costa on the fore wings. The male is fairly common in collections, but the female, which is of a dull yellowish grey instead of blue, is still very rare.

It is curious that, like the gorilla and chimpanzee, the nearest relatives of these two great West'African butterflies (if we except Papilio Ridleyanus, White, a West Árican butterfly which has some resemblance to $D$. Antimachus, though it is much smaller and redder), are to be looked for in the islands of the Eastern Archipelago.

W. F. KIRBY.

\section{A NEW ELEMENT IN THE NITROGEN} GROUP.

A NEW element appears to have been discovered by Dr.

Bayer in the residual liquors derived from the older process for the extraction of aluminium from red bauxite, and an account of it is communicated to the current issue of the Bulletin de la Société Chimique. The liquors in question consist chiefly of sulphate and carbonate of sodium, but there are also present considerable quantities of chromic and vanadic acids, and smaller quantities of molybdic, silicic, arsenic, phosphoric, and tungstic acids, together with alumina, magnesia, and lime, and an acid of the new element. In order to isolate the latter, the vanadium and chromium are first removed, the former as the difficultly soluble ammonium vanadate, and the lat er as hydrated sesquioxide. The filtered liquid is then saturated with sulphuretted hydrogen, and the sulphides, all of which are soluble in the alkaline liquid, are precipitated by hydrochloric acid. This precipitate exhibits a deep brown colour, due to the new element. When dried it presents a brown earthy appearance, and burns readily with evolution of sulphur dioxide and formation of a bright brown powder. Cuncentrated nitric acid instantly causes ignition, and formation of a deep brown solution, from which a small quantity of a yellow precipitate of a compound of molybdic and arsenic acids is deposited. The brown liquid con. tains no tin, antimony, or tellurium, but still retains traces of vanadium, molybdenum, and selenium. These elements are best removed by calcination of the sulphides immediately after their precipitation with hydrochloric acid when selenium is volatilised, treatment of the residue with ammonia and ammonium nitrate, which precipitate the last traces of vanadium as ammonium vanadate, and concentration of the filtered liquid which causes deposition of ammonium molybdate. During the concentration two distinct crops of different crystals are obtained, the first and most sparingly soluble being cubic crystals of an olive-brown colour, and the second the much more soluble ammonium molybdate. The olive-brown cubic crystals contain the new element, together with a little molybdenium. The latter is readily removed by dissolving the crystals in dilute hydrochloric acid, and passing a current of sulphuretted hydrogen through the liquid heated to about $70^{\circ}$. The new element is not precipitated by sulphuretted hydrogen in an acid solution. The filtered liquid is then allowed to evaporate in the air. At first it is bluish-violet in colour, and contains the new element in a low state of oxidation; subsequently it becomes oxidised, and the colour changes to lemon yellow. The oxide in the latter stage possesses marked acid proclivities, and probably corresponds to the formula $\mathrm{R}_{2} \mathrm{O}_{5}$. The acid itself is soluble in water, from which it is deposited in yellow crystals, which at a red heat fuse to a brownish yellow mass. Ammonia trans forms the acid into a crystalline powder of olive colour, presumably an ammonium salt, which readily dissolves in ho water and crystallises from the solution in cubes on cooling. The solution is olive green and is precipitated by strong ammonia. The solution of the acid after reduction with sulphuretted hydrogen in presence of hydrochloric acid yields with ammonia a voluminous deep violet-brown precipitate, which rapidly becomes crystalline. The precipitation is not complete, hence the supernatant liquid is coloured violet. Caustic soda and sodium carbonate likewise incompletely precipitate it, owing to solubility of the precipitate in excess of the reagent with formation of a soluble salt. Chlorides of barium and calcium produce greyish-violet precipitates of the salts of those metals.

An especially interesting reaction is that with ammonium sulphide, with which the highly oxidised yellow solution of the acid yields a deep cherry-red colouration, due to a sulfo. salt. Acids precipitate from this solution a sulphide of the colour of iron rust. Silver nitrate produces a green precipitate of the silver salt, soluble both in nitric acid and in ammonia, and if the solution in the latter solvent is effected at a moderately elevated temperature the silver salt is deposited in crystals upon cooling. Magnesia mixture gives after standing a few minutes a green precipitate analogous to ammonium magnesium phosphate, and owing to the slowness of the precipitation the latter occurs in the form of relatively large crystals ; moreover the precipitation is complete after a short time, for the liquid which at first is green becomes colourless. A yellow precipitate is likewise afforded with a nitric acid solution of ammonium molybdate, as in the case of phosphoric acid. The chlorides of the new element appear to be volatile, for very considerable loss occurs on attempting to remove by ignition any admixed ammonium salts, for instance from the solution obtained after removal of the vanadium as previously described. A yellow sublimate is produced having all the characters of a chloride of the new element, and which is readily soluble in water.

A sufficient quantity of the new element in the form of any of its compounds has not yet been accumulated to enable exact quantitative analyses to be carried out, but Dr. Bayer hopes shortly to have oblained the amount requi.ite for this purpose and for the determination of the atomic weight of the element. There appears to be little room for doubt that it will prove to be one of the missing elements predicted by Prof. Mendeléeff in the nitrogen-phosphorus group. It exhibits characteristic spectroscopic lines in the green, blue, and violet.

A. E. Tutton.

NO. 1315 , VOL. 51$]$ 